\title{
Atividade antimicrobiana in vitro do extrato de Anacardium occidentale L. sobre espécies de Streptococcus
}

\author{
Arquimedes F. Monteiro de Melo ${ }^{1 *}$, Eliane J. Vasconcelos Santos ${ }^{2}$, Luiza F. Cordeiro de \\ Souza $^{1}$, Alessandra de Albuquerque T. Carvalho ${ }^{1}$, Maria do Socorro V. Pereira ${ }^{2}$, \\ Jane S. Higino ${ }^{1}$ \\ ${ }^{1}$ Universidade Federal de Pernambuco, Centro de Ciências da Saúde, Departamento de Farmácia, 50740-521, \\ Recife, PE, Brasil, \\ ${ }^{2}$ Universidade Federal da Paraíba, Centro de Ciências Exatas e da Natureza, Departamento de \\ Biologia Molecular, 58059-900, João Pessoa, PB, Brasil
}

\begin{abstract}
RESUMO: A atividade antimicrobiana do extrato da casca do caule de Anacardium occidentale L., foi avaliada em três culturas de bactérias isoladas de biofilme dental. A atividade antimicrobiana foi conduzida em placa de Petri pelo método de difusão para determinação da Concentração Inibitória Mínima (CIM) e Concentração Inibitória Mínima de Aderência (CIMA). Inibição aureolar (CIM) foi observada com concentrações de $12,5 \mathrm{mg} / \mathrm{mL}$ em $S$. mutans e $6,25 \mathrm{mg} / \mathrm{mL}$ em $S$. mitis e $S$. sanguis. Os resultados sugerem que o extrato tem efeito na CIMA em concentrações de $0,31 \mathrm{mg} /$ $\mathrm{mL}$ em $S$. mutans e $S$. mitis e de $0,15 \mathrm{mg} / \mathrm{mL}$ em $S$. sanguis e pode ser usado terapeuticamente na odontologia como agente antibacteriano.
\end{abstract}

Unitermos: Anacardium occidentale, atividade antimicrobiana, biofilme dental.

\begin{abstract}
In vitro antimicrobial activity of an extract of Anacardium occidentale L. against Streptococcus species". The antimicrobial activity of the extract of the stem bark of Anacardium occidentale L., was evaluated in three cultures of bacteria of the dental plate. The antimicrobial activity was assayed in Petri dishes using the diffusion method for determination of the minimal inhibitory concentration (MIC) and minimal inhibitory concentration of adherence (MICA). Aureolar inhibition (MIC) was observed with concentrations of $12.5 \mathrm{mg} / \mathrm{mL}$ in S. mutans and $6.25 \mathrm{mg} / \mathrm{mL}$ in $S$. mitis and $S$. sanguis. The results suggest that the extract has effect in the MICA in concentrations of $0.31 \mathrm{mg} / \mathrm{mL}$ in $S$. mutans and $S$. mitis and of $0.15 \mathrm{mg} / \mathrm{mL}$ in S. sanguis and therapeuticly can be used in the dentistry as an antibacterial agent.
\end{abstract}

Keywords: Anacardium occidentale, antimicrobial activity, dental biofilm.

\section{INTRODUÇÃO}

O número de estudos de avaliação de compostos químicos no controle da placa bacteriana ou biofilme dental tem crescido em todo mundo de acordo com Ryscky, 1991; Lindhe, 1999; Akinpelu, 2001). Recentemente, vários estudos têm relatado atividade antimicrobiana de extratos de plantas (Ueno, 2001). Kakiuchi (1996) estudou a atividade antimicrobiana de extratos da Galla rhois, Paeoniae rubrae e Uvae ursi contra Streptococcus mutans. Os estudos de Paolino e Kashkett (1985) demonstraram a ação in vitro do extrato de cacau na inibição da enzima glicosiltransferase (GTF), que é responsável pela formação de polissacarídeo extracelular por $S$. sanguis e S. mutans.

$\mathrm{O}$ extrato da casca do caule de Anacardium occidentale L., que é largamente distribuída no Nordeste brasileiro, possui atividade antimicrobiana em diferentes organismos como Proteus morganii, Pseudomonas aeruginosa, Staphylococcus aureus, Escherichia coli e Salmonella typhi (Laurens et al, 1992). O espectro da atividade antimicrobiana do extrato da casca do caule foi analisado em culturas de Klebsiella pneumoniae que são resistentes à estreptomicina (Akinpelu, 2001). Todavia existem poucos relatos a respeito da atividade antimicrobiana de extratos sobre o biofilme dental. O objetivo deste estudo foi determinar a atividade antimicrobiana in vitro do extrato da casca do caule de A. occidentale L. em culturas de $S$. mitis, $S$. mutans e $S$. sanguis. E avaliar o efeito inibitório de doses dependentes de aderência da bactéria na superfície da placa de vidro.

\section{MATERIAL E MÉTODO}

\section{Material botânico}

Para a obtenção do extrato bruto seco (EBS) colheu-se cascas do caule de Anacardium occidentale 
L. depositadas no NUPA (Núcleo de Pesquisa e Processamento de Alimentos/ UFPB) e identificadas por J. R. LIMA do herbário "Prof. Lauro Pires Xavier", na mesma Universidade. As amostras encontram-se depositadas no referido herbário, sob o número 315000 JPB.

O material foi seco à sombra em temperatura ambiente durante $24 \mathrm{~h}$. Em seguida foi colocado na estufa a $33^{\circ} \mathrm{C}$ durante uma semana, sendo posteriormente triturada a pó. A extração foi feita em solução hidroalcoólica a $70 \% \mathrm{v} / \mathrm{v}$ e, após uma semana de maceração, foi obtido o extrato bruto por filtração. O extrato foi colocado em evaporador rotativo a $40^{\circ} \mathrm{C}$, para se obter o extrato seco, porém o extrato não chegou à secura total, sendo necessário um procedimento adicional, que foi levar o extrato para o dessecador a temperatura ambiente. Após 15 dias no dessecador, obteve-se o extrato bruto seco (EBS). O rendimento foi de $18 \%$.

\section{Cepas bacterianas}

Três culturas padrões de $S$. mitis, $S$. mutans e $S$. sanguis foram obtidas mediante solicitação na Fundação Tropical de Pesquisas e Tecnologia "André Tozello" (Campinas - SP) e no Instituto Adolfo Lutz (São Paulo - SP), respectivamente. Foram replicadas em Ágar Sangue inclinado ("slants"), e posteriormente estocados repicadas no Laboratório de Genética de Microrganismos
- Departamento de Biologia Molecular/CCEN da Universidade Federal da Paraíba.

Determinação da atividade antimicrobiana e da Concentração Inibitória Mínima (CIM) do extrato de Anacardium occidentale

A atividade antimicrobiana em placas foi determinada pela técnica de poços por difusão em ágar para o screening e para a determinação da Concentração Inibitória Mínima (CIM) do extrato de Anacardium occidentale sobre as cepas bacterianas. As cepas bacterianas foram cultivadas em caldo enriquecido Brain Heart Infusion (BHI - DIFCO); incubadas a $37{ }^{\circ} \mathrm{C}$ por 18-20 horas em microaerofilia pelo método da chama da vela. Foram realizadas perfurações no meio de cultura (ágar Mueller Hinton - DIFCO) de aproximadamente 6 $\mathrm{mm}$ de diâmetro. Nos poços foram colocados volumes de $50 \mu \mathrm{L}$ da solução do extrato, com concentrações variando de 50 a $0,04 \mathrm{mg} / \mathrm{mL}$. As placas foram incubadas em estufa bacteriológica a $37{ }^{\circ} \mathrm{C}$ em microaerofilia, por um período de 24 horas. Foram realizados estudos comparativos com a clorexidina $0,12 \%$; os ensaios foram realizados em duplicata frente a cada linhagem ensaiada. A CIM foi considerada a menor concentração do extrato que inibiu completamente o crescimento bacteriano, ou seja, apresentou halo de inibição.

Tabela 1. Concentração Inibitória Mínima em meio sólido do extrato de A. occidentale, sobre S. mitis, S. mutans e S. sanguis.

\begin{tabular}{lccccc}
\hline \multirow{2}{*}{\multicolumn{1}{c}{ Linhagens bacterianas }} & \multicolumn{5}{c}{ Diâmetro dos halos de inibição (mm) } \\
\cline { 2 - 5 } & \multicolumn{4}{c}{ Concentração do extrato (mg/mL) } \\
\cline { 2 - 6 } S. mitis & 50 & 25 & 12,5 & 6,25 & 3,12 \\
S. mutans & 19 & 15 & 14 & 12 & 0 \\
S. sanguis & 16 & 12 & 11 & 0 & 0 \\
\hline
\end{tabular}

Tabela 2. Concentração Inibitória Mínima em meio sólido do gluconato de clorexidina a $0,12 \%$ sobre $S$. mitis, $S$. mutans e $S$. sanguis.

\begin{tabular}{lccccccc}
\hline & \multicolumn{7}{c}{ Diâmetro do halos de inibição (mm) } \\
\cline { 2 - 7 } Linhagens bacterianas & \multicolumn{7}{c}{ Concentração do gluconato de clorexidina à $0,12 \%$} \\
\cline { 2 - 8 } & $0,12 \%$ & $0,06 \%$ & $0,03 \%$ & $0,015 \%$ & $0,0075 \%$ & $0,00375 \%$ & $0,001875 \%$ \\
S. mitis & 19 & 16 & 14 & 12 & 10 & 0 & 0 \\
S. mutans & 16 & 18 & 17 & 14 & 14 & 0 & 0 \\
S. sanguis & 18 & 18 & 15 & 14 & 12 & 0 & 0 \\
\hline
\end{tabular}

Tabela 3. Concentração Inibitória Mínima de Aderência (CIMA) do extrato do A. occidentale, sobre S. mitis, S. mutans e $S$. sanguis.

\begin{tabular}{lc}
\hline Linhagens bacterianas & Extrato de A. occidentale CIMA (mg/mL) \\
\hline S. mitis & 0,31 \\
S. mutans & 0,31 \\
S. sanguis & 0,15 \\
\hline
\end{tabular}




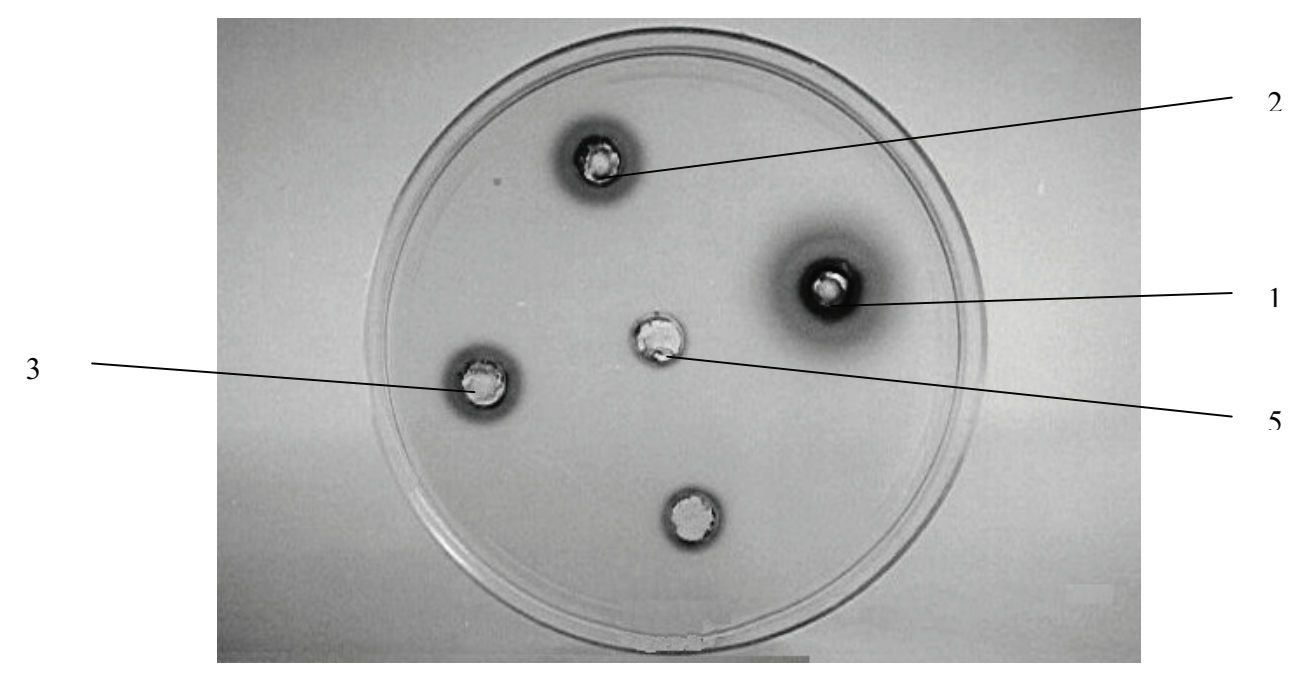

Figura 1. Atividade antimicrobiana do extrato bruto da casca do caule de $A$. occidentale L. à $5 \%$ sobre $S$. mutans, nas concentrações de $50 \mathrm{mg} / \mathrm{mL}$ (1); 25 $\mathrm{mg} / \mathrm{mL}$ (2); $12,5 \mathrm{mg} / \mathrm{mL}$ (3); $6,25 \mathrm{mg} / \mathrm{mL}$ (4) e $3,12 \mathrm{mg} / \mathrm{mL}$ (5).

\section{Determinação da Concentração Inibitória Mínima e de Aderência (CIMA)}

A Concentração Inibitória Mínima e de Aderência (CIMA) da bactéria ao vidro foi determinada na presença de sacarose a 5\%, usando-se concentrações crescentes e dobradas da solução diluída do extrato, variando de 50 a $0,04 \mathrm{mg} / \mathrm{mL}$. A partir do crescimento overnight as cepas foram sub-cultivadas a $37^{\circ} \mathrm{C}$ em caldo Mueller-Hinton (DIFCO), em microaerofilia, por um período de 24 horas obtendo-se um inóculo de $10^{6} \mathrm{UFC} /$ $\mathrm{mL}$. Foram distribuídos $1,8 \mathrm{~mL}$ do subcultivo em tubos de hemólise e em seguida foram adicionados $0,2 \mathrm{~mL}$ da solução correspondente a escala do extrato. A incubação foi feita a $37{ }^{\circ} \mathrm{C}$ por 24 horas em microaerofilia, com os tubos inclinados a $30{ }^{\circ} \mathrm{C}$. A leitura foi realizada através da observação visual da aderência da bactéria às paredes do tubo após a agitação do mesmo. A CIMA foi definida como a menor concentração do agente antibacteriano em meio com sacarose que impediu a aderência ao tubo de vidro.

\section{RESULTADOS E DISCUSSÃO}

O controle químico do biofilme dental e a prevenção da cárie dentária têm sido investigada há décadas. Um agente antibiofilme deve apresentar propriedades tais como: substantividade, inocuidade aos tecidos bucais, redução significante do biofilme bacteriano e gengivite, inibição da calcificação do biofilme, não favorecer o desenvolvimento de bactérias resistentes, não manchar os dentes, como também não alterar a gustação. Entretanto, nenhum produto comercialmente disponível preenche todos estes requisitos, apresentando alguns efeitos colaterais ou pouca eficiência (Lindhe, 1999).

É difícil a erradicação de bactérias em biofilme, bem como em abscessos com antibióticos, possivelmente devido à diminuição da taxa de crescimento bacteriano ou a proteção mecânica oferecida pelo biofilme bacteriano. A busca de terapêuticas alternativas representa a principal finalidade do estudo das propriedades do extrato de plantas.

Algumas plantas têm sido pesquisadas com o intuito de combater as infecções que acometem a cavidade bucal, principalmente as originadas pela presença do biofilme bacteriano. Ensaios in vivo utilizando a camomila (Matricaria recutita L.) como dentrifício demonstram uma redução na gengivite em 97\% dos casos relatados (Ryscky, 1991). Estudos recentes mostraram a potencialidade da Punica granatum na inibição do crescimento bacteriano das linhagens Streptococcus mitis, S. mutans, S. sanguis, S. sobrinus e Lactobacillus casei como também na inibição da síntese de glucano representada pela aderência ao vidro, sugerindo o emprego do extrato de rumã, como meio alternativo, ao controle desses microrganismos na formação do biofilme (Pereira et al., 2006).

No presente estudo, as cepas bacterianas de $S$. mitis, $S$. mutans e $S$. sanguis, foram susceptíveis à ação do extrato do caule $A$. occidentale. A inibição do crescimento apresentou-se homogênea, de acordo com o grau de concentração do extrato da planta. Houve uma diminuição proporcional do diâmetro dos halos a medida que a concentração do extrato foi diminuída,conforme a tabela 01 .

Com relação a clorexidina a $0,12 \%$ observamos 
resultados semelhantes aos resultados da ação do extrato, conforme tabela 02 .

O biofilme dental é uma película de microrganismos que se desenvolve naturalmente sobre as superfícies dos dentes. Nas fases iniciais do seu processo de formação, o biofilme bacteriano necessita de polissacarídeos extracelulares, principalmente o mutano, pouquíssimo solúvel e de alta viscosidade, permitindo a adesão, interação e multiplicação das bactérias. Por isso, neste período inicial há necessidade destes conhecimentos para um maior controle desta placa, evitando-se a instalação da cárie dentária e da doença periodontal.

No presente estudo particularmente, o extrato do caule do cajueiro apresentou potencial atividade antimicrobiana sobre $S$. mutans, conforme mostra a figura 01 .

Ao extrato do $A$. occidentale L., são atribuídas diversas propriedades farmacológicas, tais como: antidiabético, antiinflamatório, antitussígeno, antisifilítico, diurético e cicatrizante (Oliveira; Saito, 1987/1989; Jorge et al., 1996; Falcão et al., 2005; BarbosaFilho et al., 2005). Estudos sobre o efeito antiinflamatório do extrato da casca do cajueiro foram atribuídos a presença de taninos, que demonstraram atividade em ambos os modelos de inflamação aguda e crônica (Mota, 1982). O screening para atividade antibacteriana de várias plantas medicinais foi realizado na Nigéria, e o extrato da folha e casca do Anacardium occidentale mostrou boa atividade sobre $E$. coli e $P$. aeruginosa, bactérias Gram negativas (Kudi et al, 1999).

A atividade antimicrobiana de diferentes tinturas sobre $S$. mutans e $S$. sobrinus, foram analizasdos por Gebara et al (1996) demonstrando que o tomilho, cacau e própolis são efetivos na inibição de tais microrganismos, como também apresentam atividade de inibição de síntese de glucano. No entanto, as tinturas de camomila, malva e sálvia não exerceram atividade antimicrobiana.

Nesse estudo, o extrato do caule do $A$. occidentale foi efetivo na inibição da aderência das três cepas testadas, representada pela ausência de aderência ao vidro na presença de sacarose; particularmente, a maior eficácia do extrato é observada sobre o $S$. sanguis, agente mais importante na fase inicial de deposição do biofilme bacteriano. Os resultados são promissores uma vez que esses microrganismos são os maiores responsáveis pela formação do biofilme bacteriano.

\section{CONCLUSÃO}

Os resultados obtidos no presente trabalho mostram a importância das indicações terapêuticas das plantas medicinais. Assim podemos concluir que o extrato hidroalcoólico de $A$. occidentale apresenta atividade antibacteriana in vitro sobre $S$. mitis, $S$. mutans e $S$. sanguis, presentes no biofilme bacteriano supragengival, como também atividade inibitória mínima de aderência.

\section{REFERÊNCIAS}

Akinpelu DA 2001. Antimicrobial activity of Anacardium occidentale Linn. bark. Fitoterapia 72: 287-289.

Barbosa-Filho JM, Vasconcelos THC, Alencar AA, Batista LM, Oliveira RAG, Guedes DN, Falcão HS, Moura MD, Diniz MFFM, Modesto-Filho J 2005. Plants and their active constituents from South, Central, and North America with hypoglycemic activity. Rev Bras Farmacogn 15: 392-413.

Lima IO, Falcão HS, Santos VL, Dantas HF, Diniz MFFM, Barbosa-Filho JM, Batista LM 2005. Review of the plants with anti-inflammatory activity studied in Brazil. Rev Bras Farmacogn 15: 381-391.

Gebara ECE, Zardetto CGDC, Mayer MPA 1996. Estudo in vitro da ação antimicrobiana de substâncias naturais sobre $S$. mutans e S. sobrinus. Rev Odontol Univ São Paulo 10: 251-256.

Jorge LIF, Silva GA, Ferro VO 1996. Diagnose laboratorial dos frutos e folhas de Anacardium occidentaleL. (Cajú). Rev Bras Farmacogn 5: 55-69.

Kakiuchi N 1996. Studies on dental caries prevention by traditional medicines. VIII. Inhibitory effect of various tannins on glucan synthesis by glucosyltransferase from Streptococcus mutans. Chem Pharm Bull 34: 720-725.

Kudi AC, Umoh JU, Eduvie LO, Gefu J 1999. Screening of some Nigerian medicinal plants for antibacterial activity. J Ethnopharmacol 67: 225-228.

Laurens A, Mboup S, Giono A, Barber P, David-Prince M 1992. Étude de l'action antibatérienne d'extraits d'Anacardium occidentale L. Ann Pharm Fr 40: 143146.

Lindhe J 1999. Tratado de Periodontia Clínica e Implantodontia Oral. Rio de Janeiro: Guanabara Koogan.

Mota MLR, Thomas G, Barbosa-Filho JM 1985. Antiinflammatory actions of tannins isolated from the bark of Anacardium occidentale L. J Ethnopharmacol 13: 289-300.

Oliveira F, Saito ML 1987/1989. Alguns vegetais brasileiros empregados no tratamento da diabetes. Rev Bras Farmacogn 2/4: 170-196.

Paolino VJ, Kashkett S 1985. Inhibition by cocoa extracts of byosynthesis of extracelular polysaccharide by human oral bacteria. Arch Oral Biol 30: 359-363.

Pereira JV, Pereira MSV, Sampaio FC, Sampaio MCC, Alves PM, Araújo CRF, Higino JS 2006. Efeito antibacteriano e antiaderente in vitro do extrato da Punica granatum Linn. sobre microrganismos do biofilme dental. Rev Bras Farmacogn 16: 88-93.

Ryscky S 1991. The effects of officinal herbs on inflammation of gingival margin: a clinical trial with a newly formulated toothpast. $J$ Clin Dentist 2: 19-21.

Ueno LS 2001. O efeito de um verniz com clorexidina e de um verniz com flúor na redução de Streptococcus mutans no índice de placa bacteriana. Araçatuba, 110p. Dissertação de Mestrado - Faculdade de Odontologia, Universidade Estadual Paulista "Júlio de Mesquita Filho". 